\title{
Development of Student Centre Learning Methods in Block 4.3 (Elective) Through Student Exchange as Innovative Learning
}

\author{
Rika Susanti ${ }^{1, *}$ Rahmat Syawqi ${ }^{2}$ \\ * Medical Education Program Faculty of Medicine Andalas University Padang, West Sumatra 25134, Indonesia \\ *Corresponding author.Email:rikasusanti1976@yahoo.com,rikasusanti@med.unand.ac.id
}

\begin{abstract}
Learning on block 4.3 gives students the opportunity to understand concepts: Sports medicine, Hospital management, Biotechnology and biomolecular, Tradisonal cuisine minang, Article writing, Traditional medicine, Clinical management, Interactive learning design. The contribution of this block to the competency/achievement of learning in the curriculum of the course is that students are able to master the learning achievements that have been established both attitudes, general skills, special skills and knowledge. The innovation of learning methods developed in supporting learning achievements is in the form of innovative learning with student exchange methods to improve learning achievement in introductory lectures, tutorials, small group discussions, skills labs, expert lectures, practicum, plenary discussions, self-learning so that the achievement of learning both attitudes, general skills, special skills and knowledge listed in rps on each learning objective can be achieved.
\end{abstract}

Keywords: Learning Methods, student exchange methods

\section{INTRODUCTION}

Block 4.3 entitled Elective Block is a block that must be studied by semester IV students in the Faculty of Medicine Medical Education Program of Andalas University. Learning on this block gives students the opportunity to understand concepts: Sports medicine, Hospital management, Biotechnology and biomolecular, Tradisonal cuisine minang, Article writing, Traditional medicine, Clinical management, Interactive learning design. Thus the mastery of the material in Block 4.3 is important, as it will provide students with a focus on their choice. Bobok Block 4.3 is 6 SKS.

Block 4.3 or Elective Block is the block of choice that has been running for several years. The drafting of the Block refers to seven areas of competence of Indonesian doctors contained in skdi 2012, namely: Sublime professionalism, self-maturity and self-development, effective communication, information management, scientific foundation of Medical Science, clinical skills and management of health problems.

Block 4.3 The first Sub block of Sports Medicine is at the end of the student block able to explain about the importance of sports medicine, physical fitness and screening, exercise programs, exercise under certain circumstances and overcome sports injuries and rehabilitation. This subblock consists of two modules namely 1) Sports Doctor and 2) Sita Ingin Langsing.
In accordance with the strategy used namely SPICES (Student centered, Problem Based, Integrated, Community based, Elective and Spiral), in), this subblock integrated various fields of science namely Physiology, Nutrition Science, Cardiovascular, Neuromuskuloskletal. By using the student centered learning approach, students are expected to learn well during tutorials, selfstudy and plenary discussions to achieve the block's goals. To provide a guideline to students and help understand the topics given in some introductory lectures according to their respective modules. In addition, this subblock also has clinical skills that will be implemented for 2 weeks.

Block 4.3 The second sub block is hospital management is at the end of the student block able to explain the managerial pattern of the hospital for better health services, ranging from classification, licensing, process flow to the problems found. This subblock consists of one module namely "Nurul patient conflict".

Block 4.3 The third block sub block is biotechnology and biomolecular this sub block consists of 2 components, namely molecular biology components and applicative immunological components. In the molecular biology section this will be studied about: the concept of molecular 
biology and central dogma, as well as applications in the field of health, which include drug development, targeted therapy and so on. In the applicative immunology subsection is more discussed about technological developments in the field of immunology, such as monoclonal and polyclonal antibodies as well as applications in the field of health and techniques widely used in diagnostics and therapies. This sub block is held for 5 weeks.

Block 4.3 with The fourth sub block with the topic of Minang Traditional Food and Its Health Aspects is at the end of the block students understand and are able to explain about the history of Minangkabau cuisine and traditional seasonings that make a unique taste and health aspect contained in it.

Block 4.3 with the fifth sub block is article writing. In the achievement plan of Andalas University becomes a campus with world class university (WCU),, maka tuntutan then the demands to meet these standards become one thing to do. One of the standards in WCU achievement is the publication of scientific publications published in accredited journals written by both lecturers and students confiscated. Therefore, it becomes important for now by providing knowledge and understanding to students to be able to publicization of scientific work, so that students do not just make work when given lecture assignments. But it also produces published scientific work as evidence of scientific understanding.

In this sub block will be carried out lesson learn related to the determination of problems and research topics for publication, technique of writing and editing manuscripts, preparation of literature review / systematic review / meta analysis, statistical analysis (interpretation and presentation of data analysis results), search of target journals and make submissions. To support the implementation of the above objectives, students will participate in various learning activities such as introductory lectures, group projects and group project presentations.

Block 4.3 with the sixth sub block is traditional medicine. According to Permenkes No.006 of 2012 concerning Industry and Traditional Medicine Business, it is stated that traditional medicine is an ingredient or herb of ingredients in the form of plant ingredients, animal ingredients, mineral ingredients, juices (galenik), or a mixture of such ingredients that have been used for generations for treatment and can be applied in accordance with the prevailing norms in society.
In medical education at FK UNAND, traditional medicine material becomes one of the materials of choice for fourth semesterstudents. In general, the traditional medicine materials provided aim to have students have an understanding of the development of traditional medicine (OT) and know the government's policies and regulations on OT. In addition, it is expected that students have knowledge of the saintification of jamu in infectious and degenerative diseases. So that in the end they are able to educate the public about traditional medicine that is growing rapidly in the midst ofsociety based onevidencebased medicine.

To support the implementation of the above objectives, students will participate in various learning activities such as introductory lectures, group projects and group project presentations. Sub block of traditional medicine is the integration of various blocks that have been followed by students namely basic medical sciences in blocks 1.1-1.6, then integration with blocks 2.1-2.6 and blocks in year 3 and year 4 . This sub block is implemented in weeks 1 through 6 which are incorporated in block 4.3 (Elective).

Block 4.3 with the seventh sub block is clinical management. Health development is an effort implemented by all components of the nation to realize better health status than ever before, increasing awareness, willingness, and healthy living ability aimed at all members of society.

In this era of globalization, health care is very important in the survival of human beings thus the government encourages to establish health services so that the public can access the health needs that are the spearhead in development of public health. Based on Permenkes RI No. 28 of 2011, the establishment of Pratama Clinic is backgrounded by the need for health services in order to expand public services that are accessible, affordable and quality in improving the level of public health, especially the increasing and growing private clinics. This mainly faces the implementation of the National Social Security System (SJSN) in the field of health that has been implemented by the Health Insurance Implementing Agency (BPJS) since 2014.

Block 4.3 with the eighth subblock is interactive Learning Design. The method of studying in college uses the method of adult learning (higher ordered learning). Studying in college, especially medicine is emphasized on an ongoing and lifelong education. The trend of learning process is done with e-learning based and packed with interactive learning encourages the emergence of this sub block. A doctor in his career, also 
not separated from sharing science, both with colleagues and other professions.

After following this module it is expected that they already have a solid thinking order (cognitive restructuring) to be able to achieve core competencies that include a number of knowledge, skills and attitudes namely:Lifelong learning skills, Skills in communicating as a prospective doctor, Peer teacher skills especially in medicine, Learningresourchesskills that are in accordance with the technology, ability to keep up with technological advances, especially in informatics technology.

The method used in this elective sub block is project based learning. In this sub block, what students expect is to produce interactive teaching media, in various forms of programs or applications that adopt 4.0 generation informatics technology. Revolution 5.0 will also be implemented in this block.

Block 4.3 learning is prepared in the form of lectures by experts in the appropriate fields, tutorial discussions, and skills training in the laboratory. This block runs for 5 weeks, each week will be discussed 1 module, so this block will cover 5 modules. In addition to the lecture experts students will carry out clinical skills training. Each week there will be a plenary discussion with topics tailored to lectures and tutorial materials. At the end of the block will follow the evaluation of the study of block theory 4.3 in the form of a writing exam.

The contribution of this block to the competency/achievement of learning in the curriculum of the course is that students are able to master the learning achievements that have been established both attitudes, general skills, special skills and knowledge. The innovation of learning methods developed in supporting learning achievements is in the form of innovative learning with student exchange methods to improve learning achievement in introductory lectures, tutorials, small group discussions, skills labs, expert lectures, practicum, plenary discussions, self-learning so that the achievement of learning both attitudes, general skills, special skills and knowledge listed in rps on each learning objective can be achieved. Based on the above ha, the collector made the title of Student Centre Learning Method Development in Block 4.3 (Elective) through Student Exchange as innovative learning.

\section{METHODOLOGY OR OUTPUT ACHIEVEMENT STRATEGI}

\section{$2.1 R P S / R P B$}

RPS/RPB in the previous school year was revised in the form of the development of learning methods and student assessment so that it can be more effective in achieving student learning achievement by revising rps through student exchange. Curriculum development is based on analysis of problems in achieving learning achievements that were made in RPS years ago. The current innovative learning method chosen is with student exchange so that the student center learning method can be achieved effectively due to the creation of a culture of self-learning, cross-discipline and gaining valuable knowledge and experience to apply. Assessment of learning achievements is carried out in accordance with SNPT which includes the assessment of the process and results by the selection of assessment techniques in accordance with the level of competency of learning achievement stipulated in RPS. Block Handbook. Plan to change the content of the previous RPB to a new RPB that can be used as a guideline in learning.

\subsection{Proposed curriculum revisions}

The proposed revision of the curriculum to maximize the implementation of RPS is to present a matrix of curriculum namely the achievement of learning Attitudes, general skills, special skills, attitudes by clarifying the contribution of study materials in each course to the achievement of learning achievement. The implementation of the method is with Problem based learning. Problem- based learning methods (PBL).

Problem-based learning (PBL) is a strategy of learning students together in a small group through two main learning activities, namely small group discussions facilitated by a tutor and self-study.PBL is one of the more targeted and structured forms of self-directed Learning (SDL) learning methods. In contrast to pure SDL, students are given the flexibility in determining the scope of the materials studied according to their interests. In PBL learning learning coverage is more focused and specific. The scope of learning in PBL is based on specific learning objectives detailed in the curriculum. Amount of time the PBL process is also more limited than the amount of time used on SDLmurni. In pure SDL, students are given the flexibility in determining the amount of time they need to complete their inquiry, while in PBL students must complete the achievement of their learning goals within the time frame specified by the educational 
institution. In pure SDL, students can work individually based on their respective interests, so that they do not depend on the learning outcomes of other students. While in PBL, the achievement of learning goals by a student, can be influenced by the results of extracting their peer information in small groups because the information obtained by each student will be discussed to improve the knowledge they gain.

Troubleshooting is not a one-on-one goal of the PBL process. Problems or scenarios are used as a stimulus of the learning process to improve knowledge and understanding of the learning objectives set out in the curriculum. So that PBL can also be used to facilitate students to acquire basic science knowledge. As such, PBL not only facilitates the acquisition of problem solving skills, but also the acquisition of knowledge and understanding, and some other softskills skills such as communication, teamwork, independence and responsibility to learn, share information and respect others.

PBL develops various aspects of the learning process, including:

a. Knowledge - basic materials and communities are always in context

b. Skills-hard-soft-life skills - scientificthinking

c. Critical appraisal,skilled in finding information, skilled in learning actively \& independently, and learning throughout life

d. Attitudes-values of cooperation, ethics, interpersonal skills, appreciating psychosocial values

The terms relating to PBL include:

a. Curriculum adjustments packaged in modules

b. There are tutors who have undergone training

c. Proses tutorial

d. Clear blueprint of assessment, referring to learning processes and objectives

e. Room for tutorials

f. Laboratory skills (for courses that require the absence of materials related to professionalism orvocational)

g. A well-equipped library, including an electronic library
Planning Procedures

a. Lecturers identify, define, and group learning objectives that will be discussed in each PBL learning session.

b. Lecturers devise, choose or look for the right scenario to stimulate students to learn the learning objectives set for each PBL session. Scenarios can be cases, movie cuts, images, news footage and more.

c. The lecturer estimates the schedule of the implementation of the 1st PBL tutorial, the amount of self-study time required to achieve all the learning objectives set for the PBL session and the implementation schedule of the 2nd PBL tutorial.

d. Lecturers prepare a rubric of assessment of student activity during the tutorial process consisting of attendance, creativity, relevance, attitude and other assessment points that are felt necessary.

e. Lecturers divide students into small groups that can consist of 5-10 students per group, each group ideally facilitated by a tutor.

f. PBL tutors do not have to be lecturers in related fields of science discussed in the scenario.

Implementation

PBL tutorials are done in a variety of ways. The PBL model in the Doctor Education Program of the Faculty of Medicine of Andalas University is seven jumps.

a. Clarifying unfamiliar terms : Identifying and describing incomprehensible terms encountered in the scenario, the clerk noted a list of terms that remained unexplained after the discussion.

b. Problem Definition : Defining a problem or issue to be discussed, students may have different views on the issue, but all should be considered, the clerk noted the list of agreed issues.

c. Brainstorming : is a session to discuss the issues that have been agreed to be discussed. Students discuss possible explanations or hypotheses that will explain the problems that have been set out in step 2, using the year they have previously had. Students work together using their own knowledge and identify areas of knowledge that have not been 
properly explained or have not been sufficient. The clerk noted all the results of the discussion.

d. Analyzing the problems : Reviewing the discussion review on steps 2 and 3 . Then set the explanation into a tentative solution, which is restructured in theform of a scheme.

e. Formulating learning issues: Formulating learning goals, groups reaching consensus on learning goals, tutors ensuring focused learning goals, achievable, comprehensive and appropriate.

f. Self Study : Self-study. All students collect information related to each learning objective. This step is done outside of the PBL tutorial. Lecturers or tutors need to give enough time for students to selfstudy in order for all learning goals to be achieved.

g. Reporting : The group regrouped for a discussion (discussion of the 2nd tutorial). Students share and discuss their self-study results. Tutors evaluate student study results.

\section{Strategi PBL: S-P-I-C-E-S}

\section{S-tudent centered:}

a. Students are no longer students, but adults

b. Lecturer switches functions as facilitator

c. As a learning center is a science that has been designed in the form of modules (integrated \& contextual)

d. Occurs in the active learning process(mentally not phisically)

e. Students as explorers are notreceivers

$P$-roblem based

a. Learning triggers are designed in the form of problems/problems/scenarios (contained in the module)

b. Problems are designed in an integrated (horizontal, vertical, spiral) and contextual

c. Students learn (discussion) in a structured/sequential way ( seven jump)

d. Problem based is different from problem solving

\section{I- ntegrated curriculum}

a. Horizontal: material from the same level / semester is presented in one module

b. Vertical: material from different levels / semesters presented in one module

c. Spiral: proportionate repetition of the material occurs (re-offending the previous material, towards the material at the top level)

C-ommunity oriented

a. In a broad sense: the curriculum is always adapted to the changes and demands of the community, in accordance with the development of the times and SCIENCE

b. Thus the curriculum is flexible, referring to developments that occur in the community, but with a clear purpose

c. In a narrower sense: what kind of scholar does community need?- Social accountability

d. Thus a tracer study isrequired

E-lective - Early professional exposure

a. Since semester I the students have been introduced with real problems, in accordance with their profession later in life

b. Followed by skill training / studio / laboratory / field tasks

c. Thus the students from the beginning really feel and live life and activities as intellectual and professional candidates in their field.

d. Elective: prepared modules relevant to the world of work outside the mandatory curriculum

S-ystematic - Self directed learning

a. Students are trained to learn independently: active learning, thereis always an internal motivation to seek further information / deeper according to the context of learning.

b. The Faculty provides facilities

c. As a supply for life-long learning

d. Systematic : in the context of real, structured work and everything is well prepared

\subsection{Learning Technology}

The learning technology implemented is to use video, multimedia to achieve improvements to the achievements of established learning. 


\subsection{Revised RPS/RPB Implementation Plan.}

\subsection{Evaluation of successful implementation of revised RPS}

Carried out at the end of the semester using parameters: the results of learning achievement at the end of the even semester, the distribution of the final grades of UAS and the student's response to the development of the methods applied.

\subsection{Student Assessment Development.}

Development of student assessment system which includes: Assessment process, Assessment of results. Selection of assessment techniques according to competency level. Cognitive aspects, including knowledge, understanding, application, analysis, sisntesis, evaluation, and creation. Affective aspects, including students' interests and attitudes towards materials and learning processes.Psychomotor aspects, including skills that have been mastered by students.

Evaluation methods used, among others: Essay Test, Multiple Choice Test, Short answer Test,Attitude Scale, and Presentation

\subsection{Curriculum.}

Curriculum development in the Doctor Education Study Program, conducted by holding a curriculum development workshop involving internal stakeholders, external stakeholders and alumni. Further, the proposed revision of the curriculum to the faculty level.

\section{$2.8 \quad$ Learning technology}

Nifas period video, LCD, Projector

\section{CONCLUSION}

Learning outcomes for affective, cognitive or psychomotor elements. The distribution of final grades is expected to be good. The student's response to the development of learning methods and assessment system applied is expected to increase the mastery of student competency.

\section{AUTHORS' CONTRIBUTIONS}

The author's contribution are to play a role in curriculum development, curriculum revision, and improvement of graduate outcomes.

\section{ACKNOWLEDGMENTS}

Alhamdulillah, praise be to the presence of Allah SWT who Most Merciful and Most Compassionate for mercy and His grace so that researchers can complete this research on time.

\section{REFERENCES}

[1] Sajjad S. Effective teaching methods at higher education levels. Mr. J Spec Educ. 2010; 11:29- 43.
[2] Leslie. S Keiler. 2018. Teachers' roles and identities in student-centered classrooms. Keiler International Journal of STEM education

[3] Jacob, J. and Michael. 2016. Student Centered Learning - An Approach to Fostering Democracy in Schools. Student Centered Learning and Democracy.

[4] Krishnan, S. 2015. Student-Centered Learning in a First Year Undergraduate Course. International Journal of Learning, Teaching and Educational Research

[5] Buditama M. 2017. Student-centered learning approach in teaching basic grammar. Journal on English as a Foreign Language 